\title{
Cultural Creative Product Design from the Perspective of Chinese Ancient Ware Modelling
}

\author{
HeMin Du \\ Industrial design Department of creative design college, Shenzhen Technology University, Shenzhen City, \\ Guangdong Provence, 518118, China
}

\begin{abstract}
As a high value-added product, cultural creative products emphasize the cultural connotation of products. Taking tourist souvenirs as an example, the country vigorously develops the green economy represented by tourism, which drives the rise of cultural creative product design. How to design excellent cultural creative products has become a realistic topic. Ancient Chinese artefacts have inherited and accumulated a long tradition of culture, and shaped excellent creative products worthy of our learning and reference. This paper discusses the cultural connotation, cultural integration and humanistic thoughts of the design of ancient Chinese artefacts and provides useful ideas for the design of cultural creative products today.
\end{abstract}

\section{Introduction}

Cultural and Creative Industries is an emerging industry with creativity as the core generated under the background of economic globalization, emphasizing an industry in which subject culture or Cultural factors depend on individuals (or teams) to develop and market intellectual property rights through technology, creativity and industrialization [1]. In the economic transformation period of the country, the development of cultural and creative industry has been more and more valued and favoured by the government and enterprises. In recent years, the design and development of cultural and creative products dominated by the development and design of tourist souvenirs has shown a rapid development trend.

We should see that the cultural creative product design and cultural creative industry rapid development, under the appearance of the culture creative product of culture and cultural relics in shallow level and form elements extraction, imitate the surface of the article, too much emphasis on form cultural connotations excavation depth is not enough, cultural creative form similar, wen gen product homogeneity serious problem. How to dig deep into the cultural connotation and really discover the deep cultural connotation in the shape of Chinese traditional utensils has become a realistic research topic. Therefore, only by deeply understanding the ancients' humanistic thoughts on creation and then reflecting the cultural connotation of cultural and creative products at a deeper level can valuable cultural and creative products be truly created.

\section{Chinese culture in the shape of ancient artefacts}

E-mail: xtdn-dhm@126.com
The core of cultural creative design is to express people's emotions, thoughts and ideas through the product design with cultural connotation, and to endow cultural products with the value of truth, goodness and beauty. Chinese traditional culture is not only inherited in the form of thoughts, but also reflects the profound Chinese traditional culture and thoughts with the shape of objects as the carrier. To design cultural creative products from the perspective of cultural inheritance, we must first understand and absorb the profound ideological connotation contained in the shape of Chinese traditional artefacts, not just the simple physical imitation and reproduction of Chinese antiques or cultural relics.

As a daily indoor incense burner to purify the air, Boshan smoke furnace was widely used in the Han dynasty, and it was unearthed in archaeological studies at the western Han mausoleum in Xianyang and the Marquis Haihun tomb in Nanchang, Jiangxi. The word "Boshan" appeared later than the eastern Han dynasty, even to the eastern Jin dynasty. In the eastern Jinn dynasty, "Boshan" also did not refer to the smoking furnace, but also referred to the pattern on the brocade and the metal decorations on the palace [2]. The shape of Boshan furnace originated from the immortal culture of Taoism in China. The archaeologist Lu D.L. in the song dynasty recorded in archaeological map that "the censer is like Boshan in the sea, and the footer is like the four rings of the sea". In the historical legend, emperor Han Wu of the Han dynasty had a hobby of smoking incense indoors and especially believed in Taoism. Under the influence of immortal culture, he ordered people to imitate the scene of the legendary Boshan mountain to make this unique shape of Boshan incense burner. 
Table 1. Different boshan furnace products reflect the cultural connotation.

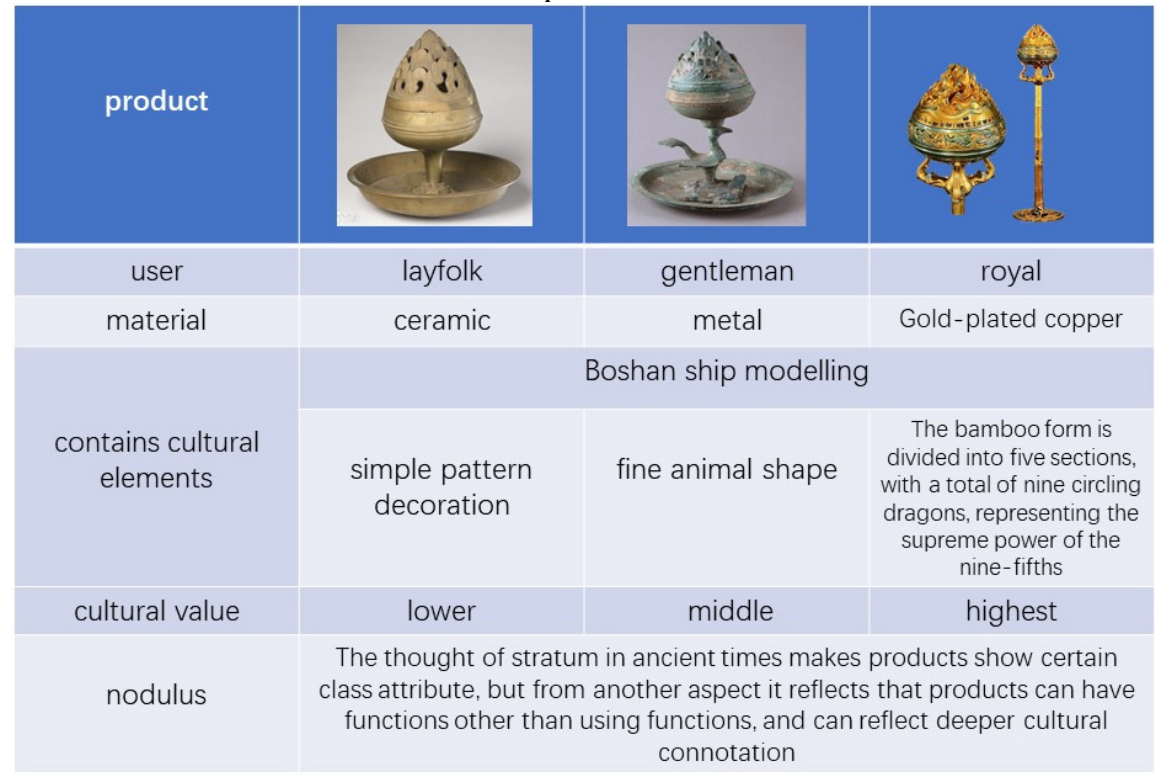

As shown in table1, the Boshan furnace in the Han dynasty, reflect the profound thoughts of imperial power and feudal class in Chinese traditional culture from the different Boshan shapes, materials and colours. It can be seen from the comparison of daily articles made in Boshan during the Han dynasty that the feudal system of rites, thoughts of celestial beings and Taoism, and thoughts of imperial power were distinct in ancient China. Under the strict hierarchy, the design of daily articles took these elements into full consideration and complied with the traditional cultural thoughts of ancient China.

\section{The fusion of foreign cultures in the shape of ancient artefacts}

While fully realizing the basic functions of the incense burner, the gilding bamboo silver festival fumigation furnace also considers the aesthetic feeling in the shape and the exquisite workmanship in the production [3]. For the graceful modelling of Boshan furnace, there are different understandings. From the modelling, Boshan furnace adopts the shape of bean, "the shape of wide mouth and narrow waist of bean is very easy to control and move [4]", which fully considers the functional requirements of the product. In addition, it is more explained that "Boshan" and "celestial mountain" are linked together. When burning incense in Boshan furnace, it produces a smoky effect, which makes people have a visual experience of fairyland. Yet another explanation for Boshan ship furnace is the generic products prairie, "Boshan ship furnace is more obvious hybrid varieties, is a blend of the steppes of Iran, as well as the characteristics of China [4]", this explanation in the interpretation of furnace Boshan ship culture connotation at the same time also proposed a new thesis, namely the cultural integration of Chinese traditional implements modelling.

Among the ancient Chinese artefacts, there are many designs incorporating foreign cultures, as shown in figure 1 , which is the golden bowl with tang dynasty Mandarin duck lotus petals unearthed from the hoard in Hejia village, southern suburb of xi 'an in 1970. The number of bowls in the gold and silver ware in the tang dynasty is very large, and the shape and structure are quite varied. Mandarin duck lotus petal grain gold bowl open, diameter $13.7 \mathrm{~cm}$, fat abdomen, flat bottom, bell-mouthing ring foot. The whole body is decorated with roe pattern, and two layers of embossed lotus petals are carved out of the outer abdomen, each layer of ten petals. In the upper lotus petal, the fox, parrot, mandarin duck and other animal shapes were chiselled, and the space was filled with flowers and plants, while in the lower lotus petal, honeysuckle was chiselled. The inner wall has two layers of lotus petals opposite the outer wall, and the inner bottom is a treasure phase flower. The outer bottom is a winged mandarin duck and honeysuckle flower. 


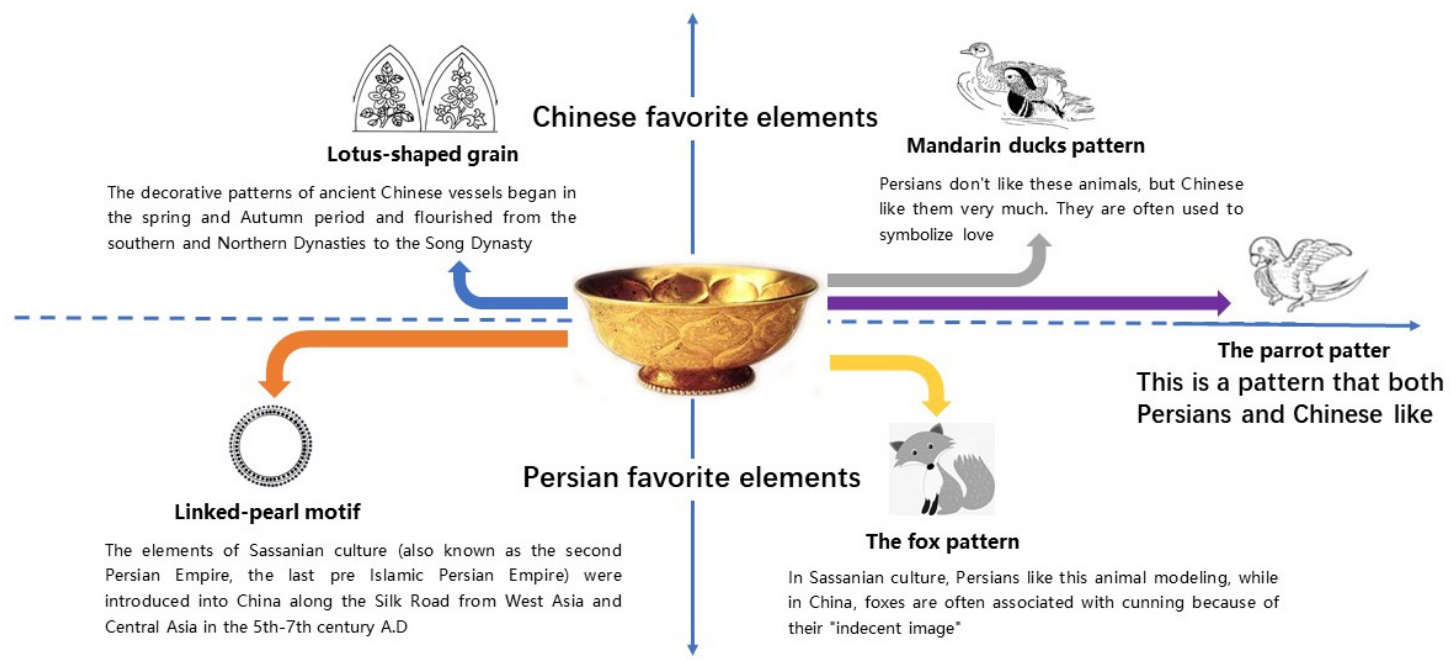

Figure 1. Mandarin duck lotus petal grain gold bowl.

As shown in Figure 1, the golden bowl with the pattern of mandarin duck and lotus petal in Tang Dynasty ingeniously integrates the ancient Persian culture and Chinese culture, and organically combines these cultural elements, fully reflecting the integration and evolution of Eastern and Western culture in the shape design of ancient Chinese artefacts. For the open modern design, more and more designers advocate the integration of Eastern and Western cultures. However, since ancient times, China has been continuously exporting Chinese excellent culture and absorbing excellent foreign culture, which is reflected in the shape of utensils and constantly creating excellent creative design.

\section{The humanistic thought of the shape of ancient artefacts}

Humanistic thought, also known as "people-oriented", from the perspective of modern design is the thought of "user-centric", but the idea is not just started to pay attention to the humanistic design of today, in contrast, in ancient China has a people-oriented, attaches great importance to the user's needs, and even the excellent design of green environmental protection.

The wild goose fish copper lamp shown in figure 2 was unearthed from the west Han tomb in Dianta village,
Shenmu county, Shaanxi province in 1985. In 2015, the tomb of Haihun tomb of the western Han dynasty in Nanchang, Jiangxi province was also excavated with a very similar wild goose fish lamp. The wild goose fish copper lamp consists by a bit of wild goose, goose body, two pieces of chimney and belt Pan lamp panel of four parts. Two lampshades can be freely rotating, can adjust the direction of lighting and defines to the wind. Wild goose abdomen can be filled with water, when the lights lit, the lamp smoke from the wild goose neck into the water, can reduce the pollution of lampblack to the room, the four parts of the lamp can be freely disassembled, easy to scrub. Such shape and structure design fully consider the use environment, lighting requirements, use and maintenance as well as the requirements of environmental protection, wild goose fish copper lamp is not only meet the function of substance use excellent products, at the same time, its modelling is element with wild goose, and the wild goose in Chinese culture, is a symbol of friendship and loyalty, goose male and female are suitable, lifetime, for a pair of geese, whether male or female goose death wild goose, left alone in a lonely goose, to death also won't find another partner. Therefore, the design of mandarin duck copper lamp is a model of bionic form design in the design of cultural and creative products, no matter the choice of theme or the design of using functions.

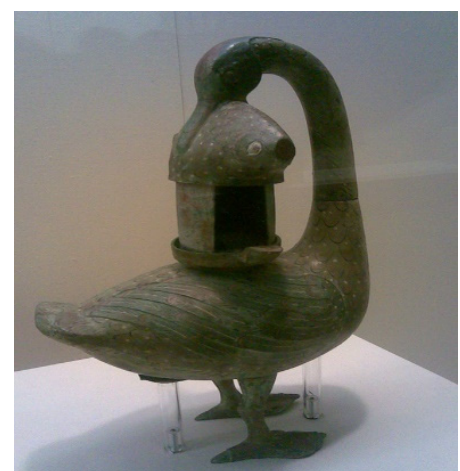

Figure 2. Wild goose fish copper lamp.

Again with contemporary tableware design compared with ancient tableware design, the modelling of three plastic tableware of figure 3 is a current airplane food standard tableware, experience tells us, however, on the 
plane or pasta to use the forks, or rice use spoons, and dinner knife and fork on the plane and the situation is very rare, as shown in figure 3 pieces of the set of tableware design will no doubt cause enormous waste of resources, is very reasonable. On the right of figure 4 is a modified design of modern cutlery integrated plastic tableware, which effectively solves the problem of tableware function design in a specific environment. Is this the optimal multi-functional design? Figure 4 (left) is the western Zhou dynasty bronze dagger utensils. The front third of the dagger spoon is knifed which can cut the meat, the top is pointed can fork meat, the body is a spoon to scoop food and the tableware design meets the knife, fork, spoon three basic function of tableware, in certain circumstances can also be used as a short weapons to meet the needs of self-defence, obviously if compare, the western Zhou dynasty Bi spoon is the ancestor of modern multi-functional design.
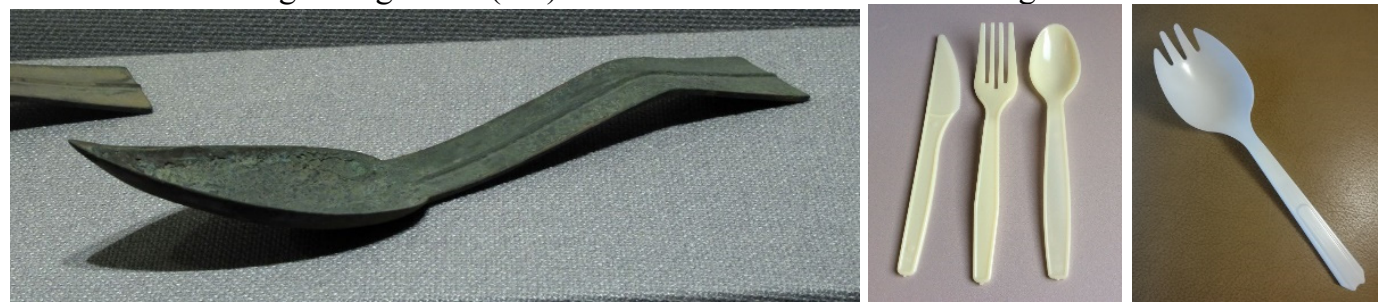

Figure 3. Design of western Zhou daggers and modern tableware.

Similar wild goose fish copper lamp and Bi key design in ancient China implements modelling, the design is implements the model of integrated design in ancient China, their design is not only considered the beautiful form and profound implication, and deeply analyses the user requirements, fully considering the mutual relations between human - machine - environment, truly reflects the product in the design of safe, healthy, comfortable, efficient and economical of human-oriented man-machine engineering design.

\section{The idea of cultural and creative design that embodies Chinese traditional culture}

Artistic design or plastic art is a process of visualizing people's spiritual world [5], and cultural creative product design pays special attention to image building at the spiritual level. Cultural creative products, especially the emerging design of tourist souvenirs, pay too much attention to the application of images and the body imitation of cultural relics, lacking connotation and deep cultural expression. Cultural and creative products should be able to reflect the distinctive characteristics of Chinese traditional culture, reflect the cultural evolution and civilization progress of the Chinese nation, and be representative of national culture, technology and advanced thinking. From the cultural level, cultural creative product should focus reflects the culture of the nationality, through the representation of the cultural product has deep symbolic meaning, as the western Han dynasty bamboo gold silver section of fuming furnace from the supreme "design, reflects the profound traditional Chinese cultural thoughts, wen gen products really become a cultural, aesthetic, functional organic carrier.

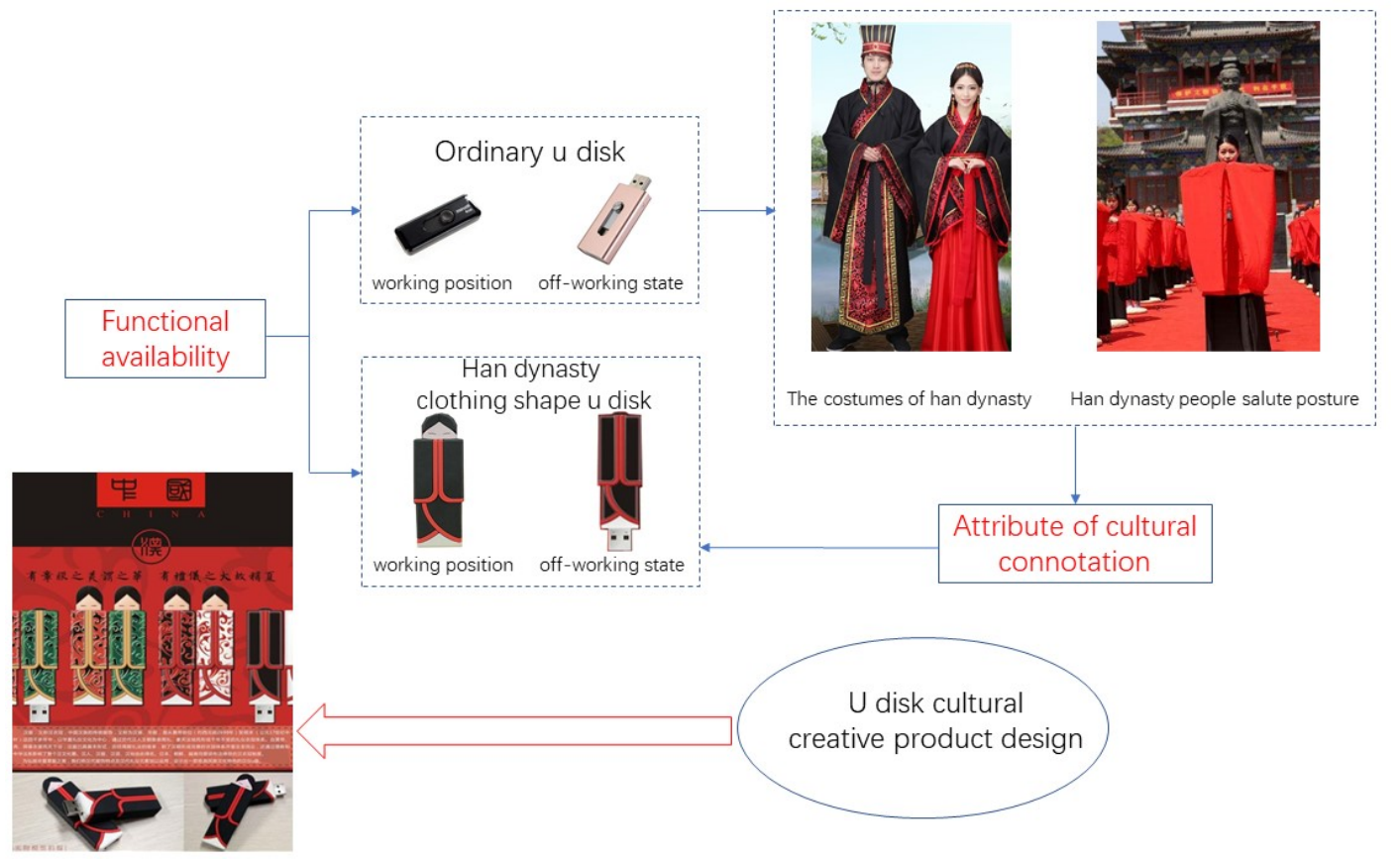

Figure 4. The Han dynasty clothing U disk design.

FIG. 4 shows the design of the USB flash disk of Han clothing, taking the etiquette of Han clothing as the design element. When using the USB flash disk, press the head, and the golden finger of the USB flash disk is extended from the bottom to insert the USB interface. This design organically combines Chinese etiquette culture with the 
use function of the product, realizing the inheritance of traditional culture in the use of the product, natural but not artificial, civilized but not rigid.

Culture creative product design is the first product design, product design, first is to consider the features of the product, and including the physical and mental functions, product structure, shape, color, material and so on all depends on the material function and spiritual function of the product demand, and, in turn, the existing elements is what determines the products material function and spiritual function. From the perspective of Maslow's demand theory, the function of material is the basic attributes of products as available content, meet people's physiological needs such as food and clothing, the changes in temperature, sexual desire, etc.), security requirements, such as protection, order and stability, etc.) or basic social needs, the spirit of the function is the function of material on the higher level of demand, respectively is a high level of social needs, such as love, friendship, sense of belonging, etc.), respect the demand (respect and affirmation) and even higher demand for selfactualization and self-transcendence.

For general products or functional products that focus on satisfying the use, more attention should be paid to economy. Especially in the modern society that pays attention to environmental protection and green environment, the design concept of minimalism and less is more is advocated. For emphasis on cultural connotation of culture creative product design, in meet the material function at the same time, focuses on reflect the inner value of the products, like gold silver bamboo section fuming furnace is a kind of symbol of identity and status, cultural creative products bearing the more cultural connotation and the spiritual elements, with the development of tourism souvenirs text and design example, tourists for wen gen products can leave a good memory, is the purpose of providing spiritual enjoyment. Therefore, the design idea of cultural creative products is to start from the level of connotation, to endure the usability of product material functions, to endue cultural features to material functions and structures, to truly achieve the organic integration of spiritual elements and material structures.

\section{Conclusion}

Represented by tourism souvenirs design culture creative product design as well as a wider level cultural creative industry in China is gradually entering the booming stage, how to grasp the cultural creative industry and even the layer of smaller cultural creative product design in the right direction, really give cultural value attribute to culture creative product, create a able to impress the audience the excellent culture of creative work, we need to consider there are still many problems. As a designer, not only need extensive mining design and shape the representation of Chinese traditional implements the design of the element, the more we need to delve into the deep cultural connotation behind the traditional artefacts, cultural relics, to explore from the perspective of national culture inheritance and carry forward the excellent cultural elements in ancient China, and the unity of nature and humanistic ideas, in-depth understanding of the ancient Chinese culture constantly progress and the development of cultural fusion, to our culture of creative product design into the successful way.

\section{Acknowledgments}

Authors wishing to acknowledge assistance or encouragement from Special innovation projects of colleges and universities in Guangdong province (No. 2018KTSCX346) and Ministry of education industryacademic cooperative education project (No. 201802201007).

\section{References}

1. Gong C.B., Yan Y.G. (2008) An Overview of Cultural and Creative Industries. In: China Radio Film \& TV Press, The Beijing.

2. Zhang X., (2013) Cross Reference-Boshanlu (Mountains Censers): The Compared Research of the Unearthed Remains and the Object-Chanting Poetry. Journal of Liaoning Normal University (Social Science Edition), 36: 395-401.

3. Lian C.H., (2014) Object modelling and belief in Han dynasty. Inn: SDX Joint Publishing Company. The Beijing.

4. Han B., (2010) Essential Activities in HanDynasty Palace and Artistic Achievement of its Device. Journal of Hundred Schools in Arts. 5:217-221.

5. Liu H.X., (2013) Cultural Exploration of Product Form. Journal of Nanjing Arts Institute(Fine Arts \& Design). 6:211-213 